\title{
Diclofenac Potassium-Induced Anaphylaxis with an Allergic Acute Coronary Syndrome and Premature Ventricular Contractions; Outpatient Clinic Management; A Case Report
}

\author{
Yasser Mohammed Hassanain Elsayed* \\ Critical Care Unit, Fraskour Central Hospital, Damietta Health Affairs, Egyptian Ministry of Health (MOH), Damietta, Egypt.
}

*Address for Correspondence: Yasser Mohammed Hassanain Elsayed, Critical Care Unit, Fraskour Central Hospital, Damietta Health Affairs, Egyptian Ministry of Health (MOH), Damietta, Egypt. E mail: dryaser24@yahoo.com

Received: 26 September 2020; Accepted: 26 October 2020; Published: 28 October 2020

Citation of this article: Elsayed Y.M.H (2020) Diclofenac Potassium-Induced Anaphylaxis with an Allergic Acute Coronary Syndrome and Premature Ventricular Contractions; Outpatient Clinic Management; A Case Report. Rea Int J of Card and Cardio Med. 1(1): 013-016. DOI: 10.37179/rijccm.000005.

Copyright: () 2020 Elsayed Y.M.H. This is an open access article distributed under the Creative Commons Attribution License, which permits unrestricted use, distribution, and reproduction in any medium, provided the original work is properly cited.

\begin{abstract}
Drug-induced disease is a common clinical entity. Drug-inducing anaphylaxis is a serious adverse effect. Several cases of allergic acute coronary syndrome or Kounis syndrome were reported. Premature ventricular contractions are the most frequent cardiac arrhythmia with or without structural heart diseases. A premature ventricular contraction is a sign of decreased oxygenation to the myocardium and anxiety but is also found in a healthy heart. A middle-aged married male patient presented to the physician outpatient clinic with syncope within one hour after ingested one tablet of diclofenac potassium $(50 \mathrm{mg})$. Diclofenac potassium-induced anaphylaxis and Kounis type I syndrome with premature ventricular contractions. Electrocardiography, oxygenation, monitoring for vital signs, and echocardiography were the done interventions. The dramatic disappearance of anaphylactic shock, Kounis type I syndrome, coronary artery spasm, and premature ventricular contractions after the traditional treatment of anaphylaxis had happened. Complete clinical and electrocardiographic recovery had achieved. The identification of drug-induced disease is a pivotal step in the diagnosis decision making of any medical problems. Diclofenac potassium can induce anaphylactic shock, Kounis type I syndrome, coronary artery spasm, and premature ventricular contractions. Kounis type I syndrome, coronary artery spasm, and premature ventricular contractions can be reversed with treatment of the cause without using anti-ischemic or ant-arrhythmic measures. Reassurance was the recommended regards diclofenac potassium-induced both coronary artery spasm and premature ventricular contractions that accompanied by anaphylaxis.
\end{abstract}

Keywords: Diclofenac Potassium, Drug-induced, Anaphylaxis, allergic angina, Kounis-Zavras syndrome, Premature ventricular contractions.

\section{Abbreviations}

ACS: acute coronary syndrome; CAS: coronary artery spasm; ECG: Electrocardiogram; ICU: Intensive care unit; IHD: Ischemic heart disease; KS: Kounis-Zavras syndrome; MI: Myocardial infarction; NSR: Normal sinus rhythm; O2: Oxygen; PVCs: Premature ventricular contractions; SCD: Sudden cardiac death; SHD: structural heart diseases; VR: Ventricular rate

\section{Introduction}

Anaphylaxis scarcely presents as an acute vasospastic coronary syndrome with or without ischemic heart disease (IHD) [1]. Acute coronary syndrome (ACS) associated mast cell activation by allergic, hypersensitivity or anaphylactoid reactions was initially designated by Kounis and Zavras in 1991. It has been named as "allergic angina" or "allergic myocardial infarction (MI)" $[2,3]$. The pathogenesis 
of allergic ACS encompasses the production of cytokines via mast cell activation, which leads to coronary artery spasm (CAS) and/ or atheromatous plaque erosion or rupture [3]. Kounis-Zavras syndrome (KS) has been triggered by a variety of drugs, food, insect stings, environmental exposures, and medical conditions [4].

Non-steroidal anti-inflammatory drugs (NSAIDs)-induced anaphylaxis precipitating CAS leading to MI in the presence of normal coronaries [5]. Three variants of KS have been described. In type I variant (most common variant, 72.6\%), the release of inflammatory mediators induces ACS with or without an increase of cardiac enzymes such as troponins. In the type II variant (22.3\%), the release of inflammatory mediators induces CAS together with plaque erosion or rupture manifesting as acute myocardial infarction. Type III variant (5.1\%) includes patients with coronary artery stent thrombosis because of an allergic reaction.

Patients with the type I variant may benefit from the treatment of the allergic reaction, which, by itself, can resolve the cardiac manifestation [6]. Premature ventricular contractions (PVCs) are the most frequent arrhythmia in patients with or without structural heart diseases (SHD) [7]. Generally, PVCs are considered benign if there is no SHD [8]. A PVC may be a sign of myocardial hypoxia [9]. PVCs can be seen in a healthy heart [9]. Frequent PVCs are associated with myocardial infarction and sudden cardiac death (SCD) in patients without known ischemic heart disease [10]. There are red flags and risk markers for premature ventricular contractions with a higher risk for SCD [11]. PVCs are a well-known trigger for malignant arrhythmias [12].

\section{Case Presentation}

A 44-year-old married, orator, Egyptian male patient presented with syncope in front of the physician outpatient clinic (POC). He was lifted with streetwalkers into the clinic. There were generalized body itching and a sense of suffocation. Symptoms had happened within one hour after ingested one tablet of diclofenac potassium (50mg). This drug was prescribed by a urologist for recurrent renal pain. The patient denied any history of other cardiac, thyroid, or other relevant diseases. Upon examination, the patient appeared a flushed face, and sweaty. There was a generalized urticaria. Tachypnea and generalized wheezy chest were the findings on chest examination.

His vital signs were as follows: blood pressure of $80 / 40 \mathrm{mmHg}$, the pulse rate of $130 / \mathrm{bpm}$; and regular, the respiratory rate of $32 /$ min, the temperature of $37.1^{\circ} \mathrm{C}$, the pulse oximeter of oxygen $(\mathrm{O} 2)$ saturation of $89 \%$, and tachycardia on heart auscultation. No more relevant clinical data were noted during the clinical examination. The initial urgent electrocardiogram (ECG) showed sinus tachycardia at 130 beats/min with a few univocal PVCs, and ST-segment depression in the anterior (I, aVL, and V-6) and inferior leads (II and aVF) leads (Figure 1A). The patient was already connected to the ICU monitor for vitals and $\mathrm{O}_{2}$ saturation follow up. Oxygen inhalation $(5 \mathrm{~L} / \mathrm{min})$ with an $\mathrm{O} 2$ generator was given. IM adrenaline $0.5 \mathrm{mg}$ of 1:1000, IV hydrocortisone $200 \mathrm{mg}$, IV chlorpheniramine maleate $20 \mathrm{mg}$, and IV normal saline $0.9 \% 1000 \mathrm{ml}$, and IV Ringer solution $500 \mathrm{ml}$.

The second ECG tracing was taken within 30 minutes after anaphylaxis management showing still borderline sinus tachycardia with VR 102 with the disappearance of PVCs and reversal of above ST-segment depressions (Figure 1B). The third ECG tracing was taken within 35 minutes after anaphylaxis management showed normal sinus rhythm (NSR) and normalization of above ST-segment depressions showed NSR with VR of 92 beats/min and normalization of above ST-segment (Figure 1C). The fourth ECG tracing was taken within 3 days after anaphylaxis showed NSR with VR of 92 beats/ min and normalization of above ST-segment depressions (Figure 1D). The complete blood count showed only eosinophilia (9\%). Later echocardiography showed no detected abnormalities with EF 66\%. The gradual dramatic response of anaphylaxis to anti-anaphylactic measures with clinical and electrocardiographic (sinus tachycardia and CAS) improvement had happened. The patient was going home within 3 hours from management with no problem. IV Hydrocortisone $100 \mathrm{mg}$ BID, oral chlorpheniramine maleate $8 \mathrm{mg}$ BID was prescribed on discharge for three days with the recommendation for future immunological consultation and follow up. Allergy Card and precautions were given to the patient for any probable future medical consultation.

\section{Discussion}

- The current case is a middle-aged married male patient presented to the physician outpatient clinic with syncope within one hour after ingested diclofenac potassium.

- The primary objective for the current case study was the presence of anaphylactic shock and Kounis type I syndrome with premature ventricular contractions.

- After the exclusion of other possible triggers in the current case, the Naranjo probability scale was used to evaluates the association between oral diclofenac potassium and development of anaphylactic shock and Kounis type I syndrome with PVCs. Naranjo probability scale in the current case study was +10 . It is meaning that there was a definite relationship between these adverse drug reactions and the causing drug, oral diclofenac potassium (Table 1).

- The secondary objective for the case study was How would you manage anaphylactic shock and Kounis type I syndrome with premature ventricular contractions.?

- The ECG ST-segment depressions which were reversed with anti-anaphylactic shock measures often indicate that this ischemic anginal insult is a coronary vasospastic abnormality of an allergic-type (Kounis-Zavras syndrome) [1-3].

- An evidence absence of coronary artery disease directed that the variant of KS was Kounis type I syndrome [1].

- The presence of premature ventricular contractions may interpret because of hypoxia [9]. or due to patient anxiety [11].

- Sinus tachycardia was either a reflective of shock or hypoxia.

- Kounis type I syndrome, coronary artery spasm, and PVCs can be reversed with treatment of the cause without using antiischemic or ant-arrhythmic measures.

- Indeed, the mechanism of oral diclofenac potassium inducing anaphylactic shock and Kounis type I syndrome with PVCs is unknown. The author thinks that the shock, hypoxia, coronary artery spasm, and anxiety may be trigger factors.

- Finally, I reported the development of anaphylactic shock and Kounis type I syndrome with PVCs within 1 hour after using oral diclofenac potassium in a 44-year old. male. 
Citation: Elsayed Y.M.H (2020) Diclofenac Potassium-Induced Anaphylaxis with an Allergic Acute Coronary Syndrome and Premature Ventricular Contractions; Outpatient Clinic Management; A Case Report. Rea Int J of Card and Cardio Med. 1(1): 013-016. DOI: 10.37179/rijccm.000005.
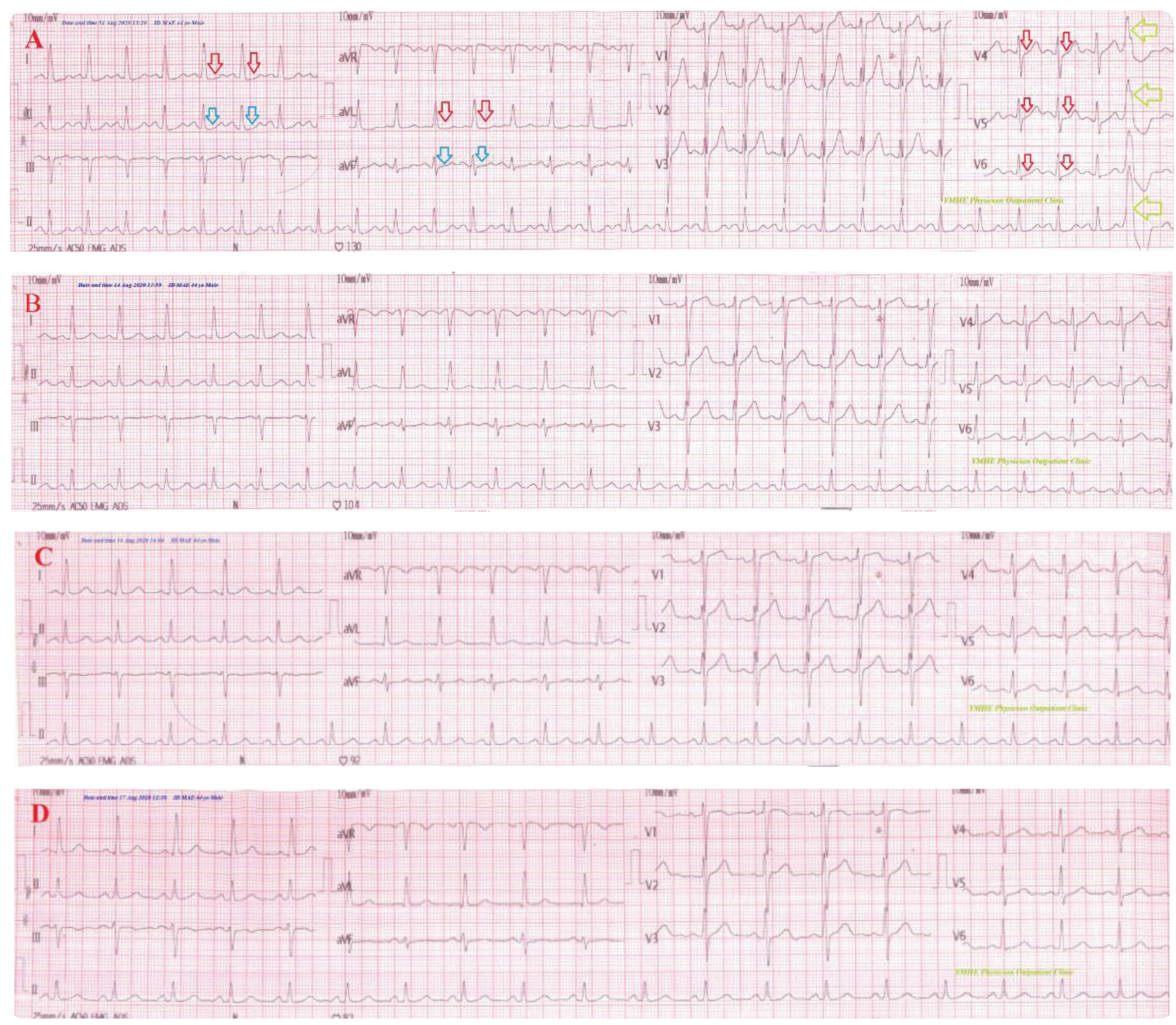

Figure 1: Serial ECG tracings

A. ECG tracing upon the patient arrival to POC showing sinus tachycardia with VR 130 beats/min, ST-segment depression in the anterior (I, aVL, and V-6; red arrows) and inferior leads (II and aVF; blue arrows ), premature ventricular contractions (lime arrows).

B. ECG tracing within 30 minutes after anaphylaxis management showing still borderline sinus tachycardia with VR 102 with reversal of above ST-segment depressions.

C. ECG tracing within 30 minutes after anaphylaxis management showing NSR with VR of 92 beats/min and normalization of above ST-segment depressions.

D. ECG tracing within 3 days after anaphylaxis management showed NSR with VR of 82 beats/min and normalization of above ST-segment depressions.

- These PVCs were few, unifocal, uniformed, and not associated using echocardiography and history with structural heart disease (SHD). So, the PVCs were benign that did not indicate any therapeutic interferences $[11,12]$.

- The main differential diagnoses for the study case are orthostatic hypotension.

- There are no known limitations in the study.

- This is the first case that reports these adverse drug reactions with oral diclofenac potassium. So, I cannot compare this case with another case because there was no similar publicized case report.

- Drug-induced diseases is a pivotal step in the diagnosis decision making of any medical problems.

- Drug side effects are a sometimes-strong way for the diagnostic challenge in clinical medicine.

\section{Conclusions}

- Diclofenac potassium can induce anaphylactic shock, Kounis 
Citation: Elsayed Y.M.H (2020) Diclofenac Potassium-Induced Anaphylaxis with an Allergic Acute Coronary Syndrome and Premature Ventricular Contractions; Outpatient Clinic Management; A Case Report. Rea Int J of Card and Cardio Med. 1(1): 013-016. DOI: 10.37179/rijccm.000005.

type I syndrome, coronary artery spasm, and premature ventricular contractions.

- The author thinks that Kounis type I syndrome, coronary artery spasm, and premature ventricular contractions can be reversed with treatment of the cause without using antiischemic or ant-arrhythmic measures.

- Aim of this study: In this manuscript, I reported the development of anaphylactic shock, Kounis type I syndrome, coronary artery spasm, and premature ventricular contractions within

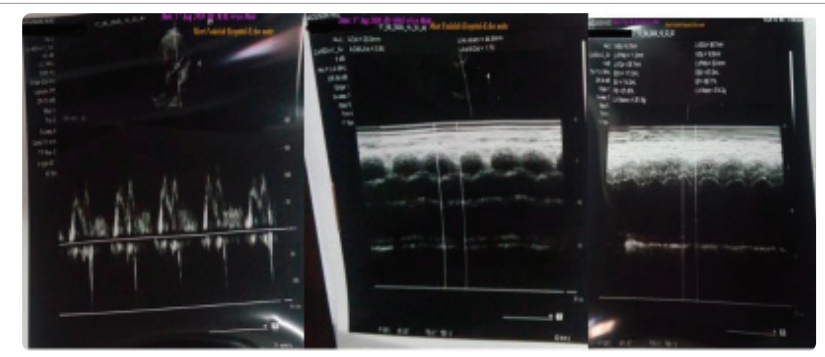

Figure 2: Echocardiography image showing no detected abnormalities.

Table 1: Naranjo Algorithm-Adverse Drug Reaction (ADR) Probability Scale in the case report.

\begin{tabular}{|l|l|l|l|l|l|}
\hline $\begin{array}{l}\text { Question } \\
\text { Yes }\end{array}$ & No & $\begin{array}{l}\text { Do Not } \\
\text { Know }\end{array}$ & Score \\
\hline $\begin{array}{l}\text { 1.Are there previous conclusive reports on } \\
\text { this reaction? }\end{array}$ & +1 & 0 & 0 & +1 \\
\hline $\begin{array}{l}\text { 2. Did the adverse event appear after the } \\
\text { suspected drug was administered? }\end{array}$ & +2 & -1 & 0 & +2 \\
\hline $\begin{array}{l}\text { 3. Did the adverse event improve when } \\
\text { the drug was discontinued, or a specific } \\
\text { antagonist was administered? }\end{array}$ & +1 & 0 & 0 & +1 \\
\hline $\begin{array}{l}\text { 4. Did the adverse event reappear when the } \\
\text { drug was readministered? }\end{array}$ & +2 & -1 & 0 & +2 \\
\hline $\begin{array}{l}\text { 5. Are there alternative causes that could on } \\
\text { their own have caused the reaction? }\end{array}$ & -1 & +2 & 0 & +2 \\
\hline $\begin{array}{l}\text { 6. Did the reaction reappear when a placebo } \\
\text { was given? }\end{array}$ & -1 & +1 & 0 & 0 \\
\hline $\begin{array}{l}\text { 7. Was the drug detected in blood or other } \\
\text { fluids in concentrations known to be toxic? }\end{array}$ & +1 & 0 & 0 & 0 \\
\hline $\begin{array}{l}\text { 8. Was the reaction more severe when the } \\
\text { dose was increased or less severe when the } \\
\text { dose was decreased? }\end{array}$ & +1 & 0 & 0 & 0 \\
\hline $\begin{array}{l}\text { 9. Did the patient have a similar reaction to } \\
\text { the same or similar drugs in any previous } \\
\text { exposure? }\end{array}$ & +1 & 0 & 0 & +1 \\
\hline $\begin{array}{l}\text { 10. Was the adverse event confirmed by any } \\
\text { objective evidence? }\end{array}$ & +1 & 0 & 0 & +1 \\
\hline
\end{tabular}

1 hour after using diclofenac potassium in a middle-aged male patient.

- Future precautions on using diclofenac potassium; specifically or NSAIDS in general are the recommendation for the current case study.

Acknowledgment: I wish to thank my wife for saving the time for my research production.

Conflict of Interest: There are no conflicts of interest.

\section{References}

1. Memon S, Chhabra L, Masrur S, Parker MW (2015) Allergic acute coronary syndrome (Kounis syndrome). Proc (Bayl Univ Med Cent). 28: 358-62. Link: https://bit.ly/3e1mVGM

2. Kounis NG, Zavras GM (1991) Histamine-induced coronary artery spasm: the concept of allergic angina. Br J Clin Pract. 45: 121-128. Link: https://bit.ly/34x6r65

3. Kounis NG (2005) Kounis syndrome (allergic angina and allergic myocardial infarction): a natural paradigm? Int J Cardiol 110: 7-14. Link: https://bit.ly/3jvsbDJ

4. Rodrigues MC, Coelho D, Granja C (2013) Drugs that may provoke Kounis syndrome. Braz J Anesthesiol 63: 426-428. Link: https://bit. $\mathrm{ly} / 3 \mathrm{muxNjF}$

5. Sim TP (2008) NSAIDS-induced anaphylaxis precipitating acute coronary vasospasm. Eur J Emerg Med 15: 48-50. Link: https://bit. ly/3e1obcY

6. Elsayed YMH (2019) Anti-shock Measures relieved Bee-Sting Anaphylaxis- Induced Kounis Type I Syndrome: A case Report. BJSTR. Link: https://bit.ly/31MOX3Z

7. Winkens RAG, Höppener PF, Kragten JA, Verburg MP, Crebolder HFJM (2014) Are premature ventricular contractions always harmless? The European Journal of General Practice 20: 134-138. Link: https://bit. ly/34uSZja

8. Jazra C, Wazni O, Jaroudi W (2015) Are premature ventricular contractions in patients without apparent structural heart disease really safe? ICFJ 2: 32-36. Link: https://bit.ly/2HxILWh

9. Kanwar G, Kumar N, Dewangan K (2015) A review: Detection of Premature Ventricular Contraction Beat of ECG. IJAREEIE. 4: 939-424. Link: https://bit.ly/31JinjC

10. Nobles MB, Langlois JP, Stigleman S (2008) Should you evaluate for CAD in seniors with premature ventricular contractions? Family Physicians Inquiries Network 57: 325-326. Link: https://bit.ly/3oywodo

11. Elsayed YMH (2019) Premature Ventricular Contractions from Benign to Seriousness - A Narrative Updating Review. Archives of Emergency Medicine and Intensive Care 2: 1-21. Link: https://bit.ly/2HCYFPA

12. Pedersen CT, G Neal Kay, Jonathan K, Martin B, Paolo Della-Bella, et al. (2014) EHRA/HRS/APHRS Expert Consensus on Ventricular Arrhythmias. Heart Rhythm 11: 166-196. Link: https://bit.ly/2HGt2Vl 